\title{
A informação no contexto arquivístico: uma discussão a partir dos conceitos de informação-como-coisa e informação orgânica
}

\author{
Natália Tognoli \\ nataliatognoli@marilia.unesp.br \\ Bacharel em Arquivologia, Mestre e Doutoranda em Ciência da Informação pelo Programa \\ de Pós-Graduação em Ciência da Informação da Unesp \\ Bolsista da Fundação de Amparo à Pesquisa do Estado de São Paulo - FAPESP.
}

Resumo: A informação sempre desempenhou um papel fundamental na vida social, no entanto, nos últimos anos, com a chamada "era da informação", as discussões acerca do objeto "informação" têm acompanhado um crescimento expoente, tanto em ambiente acadêmico, quanto no cotidiano das sociedades. Este trabalho discute a informação sob o ponto de vista das Ciências da Informação, mais especificamente da Arquivística, a partir dos conceitos de informação-como-coisa, de Buckland, e informação orgânica, de Couture, Ducharme e Rousseau enquanto substitutos do objeto "documento de arquivo".

Palavras-Chave: Informação orgânica. Informação-como-coisa. Arquivologia. Ciência da Informação

The information in the Archival Science context: a discussion based on the concepts of information-as-thing and organic information

\begin{abstract}
The information has always played a key role in social life, however, in recent years, with the so-called "information age", discussions about the subject "information" have accompanied an exponent growth, both in the academic environment, as in society. The present paper discusses the information from the point of view of Information Science, specifically from the Archival Science point of view using the concepts information-as-athing, and organic information, both developed respectively by Buckland and by Couture, Ducharme and Rousseau.
\end{abstract}

Key words: Organic Information. Information-as-a-thing. Archival Science. Information Science 


\section{Introdução}

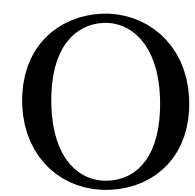
acesso à informação é tema recorrente no cotidiano das sociedades, principalmente quando é entendido no contexto dos direitos do cidadão que encontra na informação, elementos para a aquisição de conhecimento sobre os fatos de natureza pública ou privada.

Por esse e outros motivos, nos últimos anos, a informação tem sido discutida pelas mais diversas áreas do conhecimento, passando pela Comunicação, Administração, Psicologia, História até as áreas que a consideram como seu próprio objeto de trabalho, a saber, a Ciência da Informação, a Biblioteconomia e a Arquivologia.

No tocante a esta última, a discussão ainda é recente e causa desconforto àqueles que conseguem identificar somente o documento enquanto objeto de estudo da Arquivística. Por essa razão, as discussões apresentadas nesta primeira edição do periódico intitulado "Informação Arquivística" são extremamente importantes para nós, arquivistas, uma vez que nos permite pensar no paradigma que têm nos assombrado desde o início do século XXI: a passagem do estudo do documento de arquivo para o estudo da informação orgânica registrada.

Tal movimento suscitou, ainda, discussões sobre a relação da Arquivística com a Ciência da Informação, defendida por alguns autores e rechaçada por outros, apesar da inserção da primeira no campo de estudo da segunda pelas agências de fomento no Brasil que consideram a Ciência da Informação enquanto uma ciência social aplicada que engloba as disciplinas da Arquivologia, Biblioteconomia e Museologia, intituladas por Smit (1993) de "as três Marias".

Neste contexto, o presente artigo busca discutir, à luz do cenário arquivístico do século XXI, a mudança no objeto de estudo da Arquivologia e sua relação com a Ciência da Informação. Para tanto são apresentados, aqui, o conceito de informação-como-coisa (information-as- $a$ thing) de Mickael Buckland (1991), e os conceitos de informação orgânica e informação-não orgânica, cunhados pela Arquivística Integrada de Couture, Ducharme e Rousseau (1988). 


\section{Informação-como-coisa}

Antes de situarmos a informação no ambiente arquivístico, necessário faz-se adentrar nos estudos da Ciência da Informação que, desde meados do século $\mathrm{XX}$ vem desenvolvendo seus estudos em busca de elementos e conceitos para o estudo dos processos de produção, organização e uso da informação registrada e institucionalizada para que esta possa ser socializada.

No entanto, a definição de Ciência da Informação (CI) não é um consenso na área. Podemos citar mais de cinquenta definições para ela, como o fez Zins em "Conceptions of Information Science" (2005). Essa dificuldade se dá devido à interdisciplinaridade da Ciência da Informação, e à ambiguidade do próprio conceito de informação, o que chega a ser um contrassenso, uma vez que “informação tem a ver com redução de ignorância e incertezas", como bem nos explica Michael Buckland (1991, p.01).

Na clássica definição de Borko,

[...] a ciência da Informação é a disciplina que investiga as propriedades e comportamento da informação, as forças que governam o fluxo informacional, e os meios de processar a informação para uma otimização da acessibilidade e usabilidade. Ela preocupa-se com o corpo de conhecimento relacionado com a origem, coleção, organização, armazenamento, recuperação, interpretação, transmissão, transformação, e utilização da informação. (BORKO, 1968, p. 01)

Para diminuir as incertezas com relação ao conceito de informação, necessário faz-se identificar o contexto no qual ela está inserida. Para tanto, Buckland (1991) estabeleceu três significados para o uso da palavra informação: informação-como-processo (informationas-process); (2) informação-como-conhecimento (information-as-knowledge) e; (3) informação-como-coisa (information-asthing).

A primeira definição de informação, informação-como-processo, está relacionada à mudança que ocorre na mente de um indivíduo quando este é informado sobre algo. Neste caso, a palavra informação está diretamente ligada ao ato de informar, de comunicar o conhecimento sobre algum fato que ocorreu.

A segunda definição, informaçãocomo-conhecimento, é fruto da primeira definição, uma vez que, quando o indivíduo é informado sobre algo, ele adquire um conhecimento a partir daquela informação que lhe foi comunicada. 
Notadamente na terceira e última definição, informação-como-coisa, reside o objeto mais palpável da Ciência da Informação (ou seja, aquele sobre o qual incidirão diretamente os processos da $\mathrm{CI}$ ) e, consequentemente, da Arquivologia. Aqui, o termo informação é utilizado para definir objetos, dados ou documentos cuja intenção é informar sobre alguma coisa. Portanto, essa informação deve ser tangível e passível de organização, para que possa ser acessada e relacionada à CI.

Buckland (1991, p. 351) ressalta, ainda, que, a informação-como-conhecimento é intangível, não podendo ser estocada ou medida de nenhuma forma e para que possa ser comunicada, deve estar expressa ou representada em alguma materialidade, tornando-se assim, informação-como-coisa, tangível, portanto.

Deste modo, a informação-comocoisa pode ser identificada como objeto da Ciência da Informação, ou seja, uma informação registrada em um suporte. Desta forma, tem-se, como objetivo da CI, a socialização de um conhecimento produzido que só será possível a partir da materialização do conhecimento.

O leitor, neste momento, deve estar se perguntando, mas para que abordar a informação-como-coisa enquanto objeto da Ciência da Informação em um artigo que se propõe a tratar a informação no contexto arquivístico?

Primeiro, porque a Ciência da Informação é entendida, aqui, enquanto uma grande área regente das práticas das "três Marias", cujo objetivo reside no estudo dos processos de produção, organização e uso da informação, enquanto que as outras disciplinas, a saber, a Arquivística, a Biblioteconomia e a Museologia, emergem como práticas de uma ciência maior, colocando em uso esses processos. Como bem destacou Guimarães,

[...] há de se ter em conta que a Ciência da Informação, enquanto área de estudos, encontra fulcro em um conjunto de práticas que, no decorrer, ao longo do tempo, foram se consolidando, no mais das vezes ligadas a fazeres específicos contextualizados em ambiências específicas.(GUIMARÃES, 2008, p. 33)

Segundo, porque o conceito de informação-como-coisa está diretamente ligado ao conceito de documento de arquivo, uma vez que este é definido como um documento produzido por uma pessoa física ou jurídica no desenvolvimento de uma atividade específica, que terá lugar somente a partir de um registro em um 
suporte e que servirá como indício de prova e testemunho daquela atividade.

Neste contexto, Buckland (1991) define a informação-como-coisa enquanto evidências, ou seja, coisas a partir das quais alguém se informa sobre algo e que podem ser: dados, documentos e textos, e objetos. No tocante aos documentos e textos, o autor apresenta os arquivos e as bibliotecas como ambiências específicas que lidam com essa informação, conectando, assim, informação-comocoisa, documento e arquivo.

Desta feita, a caracterização da informação enquanto evidência palpável, material e que pode ser institucionalizada e socializada - documento, portanto permite a aproximação da Arquivística com a Ciência da informação, identificando, assim, documento e informação como duas faces de uma mesma moeda (SMIT, 2000), sendo impossível dissociá-las.

No entanto, conforme dito anteriormente, essa é, ainda, uma visão controversa na literatura arquivística que, raramente menciona a informação enquanto objeto de estudo do arquivista, associando somente o documento aos estudos arquivísticos.
Faz-se necessário, portanto, estabelecer dois níveis de objeto: intelectual (informação) e físico (documento de arquivo). Segundo Bellotto (2005), o objeto intelectual da disciplina é a informação, mais precisamente os dados que possibilitam a informação, enquanto que $\mathrm{o}$ arquivo - conjunto documental produzido/recebido/acumulado por entidades públicas ou privadas no exercício de suas funções - é considerado o objeto físico. Neste contexto, fica ainda mais explícita a relação simbiótica entre documento-informação.

\section{Informação orgânica}

Ainda mais próxima da informação está a Arquivística Integrada, uma das três abordagens ${ }^{1}$ que emergem no Canadá no final do século XX, com o objetivo de lidar com as novas formas de produção documental e com as novas tecnologias de informação.

A relação da disciplina com a informação se fortalece quando Couture,

\footnotetext{
${ }^{1}$ As outras duas são a Arquivística Pós-Moderna ou Funcional, cunhada por Terry Cook; e a Diplomática Arquivística, proposta por Luciana Duranti. Para um detalhamento completo, ver Tognoli, N.B. A contribuição epistemológica canadense para a construção da Arquivística Contemporânea (2010).
} 
Ducharme e Rousseau - precursores da abordagem - definem o "conjunto de informações orgânicas" enquanto objeto de estudo da Arquivística.

Buscando integrar as três fases do ciclo documental - que até o momento seguia a tradição norte americana que separa os documentos correntes e intermediários (records) dos documentos permanentes (archives), assim como seus respectivos profissionais, record manager e archivist - em uma única disciplina, a Arquivística Integrada foca seus estudos na gestão da informação orgânica e em sua importância para o fortalecimento da disciplina no século XXI.

Essa abordagem integradora foi proposta primeiramente por Couture, Ducharme e Rousseau no final dos anos 80, devido às necessidades enfrentadas pelo Arquivo Nacional do Québec em trabalhar com documentos ativos, semiativos e históricos.

[...] assiste-se hoje no Québec, a um crescimento gradual do consenso quanto à necessidade funcional e até mesmo estratégica de unir em uma só profissão os profissionais do record management e aqueles da arquivística tradicional, em torno de noções, princípios e métodos comuns [...] (COUTURE; DUCHARME; ROUSSEAU, 1988, p. 53).
Aqui, a Arquivística e o arquivista não devem mais ser vistos como simples guardiões da memória histórica e institucional. Eles participam, agora, do momento de criação dos documentos, garantindo também uma racionalização da informação e de seus processos. A contribuição dos arquivistas para a gestão da informação e a união das profissões em um só profissional constituem a base da identidade moderna da disciplina (COUTURE; DUCHARME; ROUSSEAU, 1988).

É, portanto, neste contexto, que a informação começa a ter um papel mais ativo na disciplina, pois é um elemento fundamental para $\mathrm{o}$ funcionamento $\mathrm{e}$ desenvolvimento de qualquer organização devendo ser gerida de forma eficaz.

Emergem, assim, os termos informação orgânica e informação nãoorgânica enquanto frutos da abordagem quebequense. Aqui, a informação orgânica é definida como aquela que é produzida e/ou recebida no âmbito de uma atividade, e a produção de uma ou mais informações orgânicas darão origem aos arquivos da instituição. Já as informações nãoorgânicas são aquelas contidas em documentos bibliográficos, como as publi- 
cações e os materiais de referências, por exemplo.

Além disso, a informação orgânica pode ter um valor primário e um valor secundário, correspondendo aos valores dos documentos de arquivo colocados primeiramente por Schellenberg, em 1956.

Para Delmas (1996), a definição de informação orgânica está diretamente ligada àquela de fundo, uma vez que segundo o autor, qualquer informação, no momento de sua criação ou recebimento por um organismo ou indivíduo no curso de suas atividades, por esse fato em si, é arquivística e faz parte dos fundos de arquivo de seu autor ou recebedor, com o mesmo status dos documentos mais antigos.

Como consequência da mudança no foco da disciplina, a gestão de documentos também dará lugar à gestão da informação orgânica, que desempenhará um papel decisivo, no que tange à organização e disseminação das informações e à rapidez nos processos de tomada de decisão no interior das organizações.

Para que as organizações possam usufruir de um sistema de gestão que ofereça uma solução para os problemas gerados pela produção e acúmulo desordenado de informações, Couture, Ducharme e Rousseau (1988) criaram um programa em três fases, por meio do qual a Arquivística pode demonstrar sua grande contribuição no campo da gestão integrada da informação orgânica.

A primeira fase corresponde à produção, difusão e acesso à informação orgânica, onde a informação é concebida de maneira estruturada e inteligível. É registrada em um suporte adequado, sendo posteriormente inserida no canal de difusão apropriado, a fim de ser facilmente acessível e de permitir uma comunicação máxima que tenha em conta tudo quanto do ponto de vista legal, cultural e tecnológico [...] A segunda fase componente do programa diz respeito à classificação e à recuperação da informação [...] a terceira e última fase centra-se na proteção e na conservação da informação. A informação bem protegida e conservada segundo normas técnicas e materiais precisos pode ser facilmente comunicada (ROUSSEAU; COUTURE, 1998, p $68)$.

É justamente por meio da implantação de um programa que englobe a produção, a difusão e acesso, a classificação, a recuperação e a preservação da informação que a Arquivística poderá exercer seu papel no seio da gestão da informação, apresentando seu papel, integrando todas as fases do ciclo vital dos documentos, assegurando uma unidade e continuidade no trabalho arquivístico. 
Observa-se, portanto, que ao definir o objeto da Arquivística como a informação orgânica registrada, a abordagem quebequense busca inserir a disciplina na chamada "era da informação", integrando gerenciador de documentos (ativos e semi-ativos) e arquivista (documentos permanentes) em uma só profissão, de maneira a garantir a sustentação da Arquivística em um novo contexto de produção de informações.

Vale a pena destacar, aqui, que, no Brasil, nunca houve uma separação entre as profissões, tal como ocorre na América do Norte, seguindo muito mais uma tradição arquivística europeia, baseando-se nos estudos espanhóis e franceses, trabalhando com o ciclo vital dos documentos como parte de uma única área, desde a década de 1970. No entanto, a contribuição da abordagem integrada para a Arquivística brasileira e o motivo pela qual é citada neste trabalho, é, justamente a integração entre informação e documento. Os teóricos da abordagem quebequense conseguem situar a disciplina no seio das discussões sobre a gestão da informação, colocando o arquivista como um gestor, muito mais do que um guardião de documentos.
A proposta dos teóricos é um ponto de partida para uma consolidação da Arquivística enquanto uma disciplina integrada e autônoma, capaz de oferecer as soluções para os problemas colocados às organizações na era da informação, no que tange à produção e organização de informações orgânicas registradas.

Neste contexto, pode-se afirmar que, mais do que o documento, a informação registrada é o elemento responsável pela interdisciplinaridade da Arquivística, possibilitando sua relação com as demais ciências sociais aplicadas, notadamente com a Ciência da Informação.

Destaca-se, portanto, a enunciação da Arquivística Integrada como um dos fatores responsáveis em estabelecer essa relação, à medida que traz à Arquivística uma nova visão de seu objeto de estudo, contribuindo para uma renovação da disciplina face às mudanças ocorridas no final do século XX e começo do XXI.

A abordagem canadense demonstra ainda, ao identificar a informação orgânica registrada como seu objeto de estudo, que o binômio documento/informação não é uma exclu- 
sividade da Biblioteconomia ou da Museologia, e que, o arquivista, pode e deve tratar a informação como elemento central de seu trabalho.

\section{Considerações finais}

Buscou-se, com este trabalho, apresentar os conceitos de informaçãocomo-coisa e informação orgânica que têm permeado a teoria arquivística, desde final do século $\mathrm{XX}$, proporcionando uma aproximação com as demais ciências da informação, notadamente a partir do conceito de informação enquanto objeto central da Arquivística.

O conceito de Buckland é fundamental para situar a informação e o documento enquanto partes de uma mesma entidade, lados de uma mesma moeda. Tal conceito tem a capacidade de aproximar a Arquivística da Ciência da Informação e da própria informação, notadamente quando o autor identifica a informação-como-coisa enquanto algo palpável, passível de organização.

O conceito de informação orgânica consegue tirar o documento do foco do arquivista, fazendo-o compreender que mais importante que o suporte, é a informação que ele carrega, e que esta informação é produzida em um contexto arquivístico.

$\mathrm{Na}$ chamada sociedade da informação, milhares de informações são geradas a cada segundo e sua organização, recuperação e acesso devem ser mais eficientes, otimizando gastos, espaço e recursos humanos. Portanto, é importante que a Arquivística, enquanto a disciplina responsável pelo tratamento do conjunto de informações orgânicas registradas, associe-se às demais ciências da informação, para validá-la enquanto disciplina autônoma e interdisciplinar, afirmando seus princípios e fortalecendo sua prática, no âmago da gestão dessas informações.

Conclui-se, finalmente, que, ao identificar a informação enquanto objeto de estudo, a Arquivística é inserida na chamada era da informação, e seu profissional passa a ser considerado um gestor da informação, muito mais do que um guardião de papeis velhos. Essa identificação permite, portanto, que a profissão do arquivista possa a ser central nas organizações, indo além de velhos porões, traças e mofos, como figura no imaginário popular, para um papel central 
no seio das organizações, onde é o seu lugar.

\section{Referências}

BELlOTTO, H. L. Archivística, archivos y documentos. São Paulo: ARQ-SP, 2005.

BORKO, H. Information Science: what is it? American Documentation. vol.19, n. 1, 1968, p. 3-5.

BUCKLAND, M. K. Information as thing. Journal of the American Society for Information Science. vol. 42, n. 5, 1991, p. 351-360.

COUTURE, C.; DUCHARME, J.; ROUSSEAU, J. L'archivistique a-t-elle trouvé son identité? Argus, vol. 17, n. 02, 1988, p. 51-60.

COUTURE, C.; ROUSSEAU, J. Les archives aux XX siècle: une réponse aux besoins de l'administration et de la recherché. Montréal: Université de Montréal, 1982.

DELMAS, B. Manifesto for a Contemporary Diplomatics: From Intitutional Documents to Organic Information. American Archivist, vol. 59 (fall), 1996, p. 438-452.

GUIMARÃES, J.A.C. Ciência da Informação, arquivologia e biblioteconomia: em busca do necessário diálogo entre o universo teórico e os fazes profissionais. In: GUIMARÃES, J.A.C; FUJITA, M.S.L. (eds.). Ensino e pesquisa em biblioteconomia no Brasil: a emergência de um novo olhar. Marília: Cultura Acadêmica e Fundepe, 2008, p. 33-43.

SMIT, J.W. O documento audiovisual ou a proximidade entre as três Marias. Revista Brasileira de Biblioteconomia e Documentação, vol. 26, n. 1, 1993, p. 8185.

SMIT, J. W. Arquivística, Biblioteconomia e Museologia: o que agrega estas atividades profissionais e o que as separa? Revista Brasileira de Biblioteconomia e Documentação, vol. 1, n. 2, 2000, p. 11-26.

TOGNOLI, N. B. A contribuição epistemológica canadense para a construção da Arquivística Contemporânea. 2010. 120 f. Dissertação (Mestrado em Ciência da Informação) Faculdade de Filosofia e Ciências, Universidade Estadual Paulista, Marília, 2010.

ZINS, C. Conceptions of Information Science. Journal of the American Society for Information Science and Technology, vol. 58, n. 3, 2007, p. 335350. 